\title{
The effects of laterality in stage IV breast cancer patients at initial diagnosis; much work is needed!
}

\author{
Kadri Altundag ${ }^{1}$
}

Received: 19 December 2016/ Accepted: 2 January 2017 / Published online: 6 January 2017

(C) Springer Science+Business Media New York 2017

\section{To the Editor,}

I want to congratulate Leone and colleagues for their article in which they analyzed prognostic impact of metastatic pattern (MP) in 9143 stage IV breast cancer patients at initial diagnosis. They showed substantial differences in overall survival according to MP and found that tumor subtypes have a clear influence among other factors on specific sites of metastases [1]. Among the study variables, laterality was also analyzed. Interestingly, left laterality was found to be more frequent than right laterality with trend toward significance (48.7 vs. $46.2 \%$ in all groups, 49.1 vs. $45.3 \%$ in bone only groups, $p=0.06$ ) in IV breast cancer patients at initial diagnosis. Development of metastasis in patients with breast cancer (BC) is the most important negative prognostic factor, and this process mainly begins with lymphatic involvement. Therefore, axillary, subclavicular, internal mammary, or supraclavicular nodal involvement is a crucial step before metastasis. Anatomical differences between the right and left lymphatic drainages of the breasts may significantly affect the rate, site, and time to development of distant metastasis. We hypothesized that clinical variations related to laterality may be partly due to the following factors: different number of involved lymph nodes in each half of the body and/or different lymphatic flow between the right and left side. As previously stated, the left lymphatic duct, which takes the lymphatic flow of the left

This letter to the editor refers to the article available at doi: $10.1007 /$ s10549-016-4066-7 and a rebuttal letter to this letter to the editor is available at doi: 10.1007/s10549-017-4104-0.

Kadri Altundag

altundag66@yahoo.com

1 MKA Breast Cancer Clinic, Tepe Prime, Cankaya, 06800 Ankara, Turkey breast, takes also the lymphatic drainage of lower extremities, left abdomen, left hemithorax, left side of the head and neck, and the left arm, amounting to drainage of threefold greater area compared to that of the right lymphatic duct, whereas the right lymphatic duct, which drains the right breast, only receives the lymphatics of the organs above the level of umbilicus and right hemithorax, right side of the head and neck, and the right arm. In addition, the right lymphatic duct is much shorter and has a simpler structure compared to the left lymphatic duct [2]. We then explored if laterality is an independent prognostic factor for metastasis in N3 breast cancer patients. An interesting finding was that despite the higher $\mathrm{T}$ stage in the right breast cancer group, patients with left breast cancer developed a significantly higher rate of overall distant and axial bone metastases correlated well with current study findings and had shorter time to first metastasis, supporting our hypothesis of the negative effect of laterality [3]. In conclusion, the effects of laterality need to be explored throughly in stage IV breast cancer patients at initial diagnosis.

Compliance with ethical standards

Conflicts of interest The author indicated no potential conflicts of interest.

\section{References}

1. Leone BA, Vallejo CT, Romero AO, Machiavelli MR, Pérez JE, Leone J, Leone JP (2016) Prognostic impact of metastatic pattern in stage IV breast cancer at initial diagnosis. Breast Cancer Res Treat. doi:10.1007/s10549-016-4066-7

2. Skandalakis JE, Skandalakis LJ, Skandalakis PN (2007) Anatomy of the lymphatics. Surg Oncol Clin N Am 16(1):1-16

3. Karatas F, Sahin S, Erdem GU, Ates O, Babacan T, Akin S, Sever AR, Ozisik Y, Altundag K (2016) Left laterality is an independent prognostic factor for metastasis in $\mathrm{N} 3$ stage breast cancer. J BUON 21(4):851-858 